\title{
III
}

CENTRO STUDI LUCA D'AGLIANO

www.dagliano.unimi.it

CENTRO STUDI LUCA D’AGLIANO

DEVELOPMENT STUDIES WORKING PAPERS

N. 186

October 2004

\section{The Puzzling Persistence of the Distance Effect on Bilateral Trade}

\author{
Anne-Cèlia Disdier*
}

Keith Head**

*Centro Studi Luca D’Agliano and TEAM, Université de Paris I **Sauder School of Business, University of British Columbia 


\title{
The Puzzling Persistence of the Distance Effect on Bilateral Trade*
}

\author{
Anne-Célia Disdier ${ }^{\dagger} \quad$ Keith Head ${ }^{\ddagger}$
}

September 29, 2004

\begin{abstract}
One of the best established empirical results in international economics is that bilateral trade decreases with distance. Although well-known, these results have not been systematically analyzed before. We examine 1052 distance effects estimated in 78 papers. Information collected on each estimate allows us to test hypotheses about causes of variation in the estimates. We focus on the question of whether distance effects have fallen over time. We find that the negative impact of distance on trade is not shrinking, but increasing slightly over the last century. This result holds even after controlling for many important differences in samples and methods.
\end{abstract}

JEL classification: C10, F10

Keywords: shrinking world, globalization, meta-analysis

*Previously titled: "Exaggerated Reports of the Death of Distance: Lessons from a Meta-analysis." We thank Deborah Swenson for many valuable suggestions.

†Centro Studi Luca D’Agliano and TEAM, Université de Paris I Panthéon Sorbonne, 106-112 Bd de l'hôpital, 75647 Paris CEDEX 13, France. Tel/Fax: (33) 1440782 67, Email: adisdier@univ-paris1.fr

${ }^{\ddagger}$ Sauder School of Business, University of British Columbia, 2053 Main Mall, Vancouver, BC, V6T1Z2, Canada. Tel: (604)822-8492, Fax: (604)822-8477, Email: keith.head@ubc.ca 


\section{Introduction}

Conventional wisdom holds that technological progress is causing the impact of distance to disappear. In her book The Death of Distance, Frances Cairncross announces that "The death of distance as a determinant of the cost of communicating will probably be the single most important force shaping society in the first half of the next century." Kishore Mahbubani, Singapore's ambassador to the United Nations, states that "Distance has disappeared. The world has shrunk to a global village..." (quoted in The Economist, February 20th, 2003). Some economists also see a major decline in the importance of transport costs. In particular, Glaeser and Kohlhase (2004) conclude "Certainly it is an exaggeration to claim that moving goods is free, but it is becoming an increasingly apt assumption."

Most trade economists disagree with the conventional wisdom expressed above. Anderson and van Wincoop (2003) begin their recent survey with the statement, "The death of distance is exaggerated. Trade costs are large..." Leamer and Levinsohn (1995) refer to estimates showing that distance reduces bilateral trade as "some of the clearest and most robust findings in economics." There is, however, little consensus about the exact magnitude of the distance effect. Two surveys of the empirics of international trade have asserted quite different numbers. Leamer and Levinsohn (1995) mention two early studies and then claim "These and many subsequent studies have found a distance elasticity of about -0.6." Overman et al. (2003) state "the elasticity of trade volumes with respect to distance is usually estimated to be in the interval -0.9 to -1.5 ." They provide references to three studies as examples. Note that Leamer and Levinsohn's point estimate lies outside the interval proposed by Overman et al. Here we conduct what we believe to be the first large-scale systematic examination of the magnitude of the distance effect and the causes of its cross-study variation.

We investigate the sensitivity of the distance coefficient estimated within a gravity equation to time period, choice of control variables, and estimation techniques used in the studies. The impact of these study characteristics on the estimated distance effect can shed light on the reasons why distance has mattered in the past and on the extent that it will likely matter in 
the future. Our estimates come from studies of short-range trade between American states as well as studies that span the world. Most studies lump all goods together but we also include a number of estimates that employ disaggregated trade flows. Thus we are able to assess the impact of factors that usually vary little within samples by combining results estimated from very different data sets.

Our most interesting results concern the evolution of the distance effect over time. This subject has generated a recent literature. Brun et al. (forthcoming) and Coe et al. (2002) conduct panel estimation of gravity equations from 1962-1996 and 1975-2000, respectively. For standard gravity specifications, both studies find rising distance effects. Brun et al. are able to find a declining trend for distance effects only when they estimate an "augmented" specification confined to the sample of rich countries. Coe et al. find declining distance effects in their "non-linear" version of the gravity equation. Instead of estimating gravity equations, Carrère and Schiff (2004) weight bilateral distances by bilateral trade flows to calculate an "average distance of trade" by country from 1962-2000. They find that these distances are falling over time, corroborating the gravity equation results of larger distance effects. One possible cause of rising distance effects for the aggregate bilateral trade flows used in the preceding studies would be a shift in composition towards industries with relatively high distance effects. Berthelon and Freund's (2004) study of industry-level trade finds that 75 percent of industries do not exhibit significant changes in the distance effect. The significant changes are almost all in the direction of a larger distance effect over the 1985-2000 period. We offer a longer term perspective on the distance effect than these papers by collecting estimates from studies that use trade data going back as far as 1870 .

The remainder of the paper is structured as follows. Since meta-analyses are not very common in economics, we briefly discuss the rationale and some frequent criticisms of the approach in Section 2. We describe our sample in Section 3 and show that there is huge variation in estimated distance effects. To permit interpretation of this variance, Section 4 describes three important sources of differences in results and proposes a number of ways to investigate the contribution of each variable. In Section 5 we present "meta-regression" 
results on the causes of distance effect variation. Our most striking result is that, after slightly decreasing in the first half of the century, the distance effect begins to rise around 1950. Section 6 subjects our sample of distance effect estimates to two tests for "publication bias." We conclude in Section 7.

\section{Meta-analysis: What is it good for?}

A "meta-analysis" is a quantitative assessment of results from original analyses. Individual empirical analyses differ in the use of various econometric specifications, explanatory variables, data, sample sizes, time periods, etc. These differences make it difficult to compare results. Summarizing and combining results and study characteristics, meta-analysis offers explanations of study-to-study variation and could therefore yield answers to subjects for which no consensus appears in the literature. ${ }^{1}$ Meta-analysis can also be used to test for publication bias, and could provide useful guidelines for future research and for policymakers (Florax et al., 2002).

Economists have increasingly employed meta-analytical approaches. The different topics of investigation include the union-nonunion wage gap (Jarrell and Stanley, 1990), Ricardian equivalence (Stanley, 1998 and 2001), gender wage discrimination (Stanley and Jarrell, 1998), taxes and foreign direct investment (de Mooij and Ederveen, 2003), productivity spillovers (Görg and Strobl, 2001), the effects of currency unions on trade (Rose, 2004), the relationship between location decisions of firms and environmental regulations (Jeppesen et al., 2002), transport externalities (Button, 1995), and a variety of other environmental and transport issues (summarized in van den Bergh and Button, 1997).

Meta-analysis offers considerable advantages relative to qualitative literature reviews. The latter suffer from a potential selection bias, resulting from the fact that the selection of papers is based on the only choice of the reviewer, which could intentionally or not ignore important

\footnotetext{
${ }^{1}$ For an introduction to the use of meta-analysis in economics, see Stanley and Jarrell (1989) and Florax et al. (2002).
} 
contributions of the existing literature. Ideally, a meta-analysis includes all papers on a particular subject or, failing that, a representative and randomly selected sample. Qualitative reviews often focus attention on an even smaller set of papers that the reviewer considers to have superior methodology. Meta-analysis can be more systematic than qualitative reviews, summarizing statistically the whole body of work on a subject without the impressionistic or egotistic approach taken by the worst qualitative surveys. A less obvious benefit of metaanalysis is that one can use regressions on study characteristics to determine which features of statistical analyses have the greatest impact on results. Findings of this type can guide future research.

Several criticisms have been raised, however, against meta-analysis. A first criticism concerns the heterogeneity among studies included in the meta-analysis. Glass et al. (1981) refer to this criticism as the "Apples and Oranges Problem." Examples would include the combination of studies with different outcome variables or different explanatory variables. Our study considers only estimates of the effects of geographic distance on bilateral trade. Even if studies measure the same relationships they cannot be averaged if they measure effects using different units. Our study benefits from the near universal use of the gravity equation that estimates a units-free elasticity. Finally, different statistical methods might lead to estimates that essentially measure different "experiments." For instance instrumental variables estimates can have different probability limits than ordinary least squares estimates of the same relationship. We view this not as a problem for meta-analysis but rather as an opportunity for systematic inquiry into the influences of method on effect size. Thus, as we detail subsequently, we use method dummy variables in our meta-regression analysis.

A second criticism is related to the quality of the underlying studies. Because of the inclusion of all studies on a given subject, results from shoddy studies may be given undue weight in meta-analysis. This objection is partially true, but it is only an argument against meta-analysis if we believe there is no way to quantify the quality of the analysis, and therefore only the qualitative reviewer can determine the reliable study results. On the contrary we believe that it is possible to extract useful information from poor studies and that objective 
and quantitative methods of assessing study quality can be incorporated into meta-analysis.

A third weakness of meta-analysis results from a potential presence of publication bias. The tendency among editors of academic journals to publish results that are statistically significant could bias the results of the meta-analysis. This problem also occurs for qualitative literature reviews. We employ standard meta-analysis methods to test for the presence of such a bias in our sample.

\section{The Distance Effects Dataset}

Distance effects are estimated as a parameter in the gravity equation. Originally based on a analogy with Newton's law, the gravity equation in trade takes the following form:

$$
x_{i j}=G \frac{Y_{i}^{\alpha} Y_{j}^{\beta}}{D_{i j}^{\theta}}
$$

In this equation $x_{i j}$ is either exports from $i$ to $j$ or the total volume of trade between $i$ and $j$. $Y_{i}$ and $Y_{j}$ are, respectively, the economic "masses" of the exporting and importing countries and $D_{i j}$ is the distance separating them. G corresponds to the "gravitational constant" and is modeled as a log-normally distributed random term in the basic gravity equation. ${ }^{2}$ After taking natural logs we have

$$
\ln x_{i j}=\zeta+\alpha \ln Y_{i}+\beta \ln Y_{j}-\theta \ln D_{i j}+\epsilon_{i j}
$$

We define $\theta$ (which equals 2 in Newton's equation), as the "distance effect", the negative of the elasticity of bilateral trade with respect to distance.

The first step of the meta-analysis is to construct a database of estimates of $\theta$. Hundreds of empirical papers studying the bilateral trade flows are based on the gravity equation. Therefore, it appears practically impossible to include all papers in our database. However, this abundance makes the construction of a representative sample of this literature easier. To

\footnotetext{
${ }^{2}$ So-called augmented gravity equations add a plethora of other determinants of bilateral trade.
} 
maximize the replicability of our meta-analysis, we initially followed Stanley's (1998) approach and restricted our research to the Econlit database. We searched using the keywords "gravity equation," "gravity and distance and trade" in the subject or the title. Gravity equations are extensively used in the recent empirical literature on border effects. To include these studies, we also searched for the keywords "border and distance and trade" and "home bias and trade".

Given our interest in long run trends in the distance effect, we particularly wished to find studies of early periods. Hence, we adjusted our keywords and added the search terms "gravity and history and trade." Note that this search procedure should not bias our results since it selects based on a control variable, not the dependent variable.

We excluded several papers from this original sample. First, we only used papers written in English. Second, we excluded one paper that met our Econlit search criteria but that only estimated distance effects for international equity flows. The final sample based on Econlit keywords comprises 55 papers, 44 of which are published in academic journals, 4 are chapters in books, and 7 are unpublished manuscripts. This sample omits many well-known papers estimating distance effects. Also the sample seems to draw too heavily on lesser journals. Therefore, we augmented our sample by a searching in JSTOR for papers published in the American Economic Review and the Review of Economics and Statistics. We also searched the website of the Journal of International Economics. This supplemental search identified 30 papers, 7 of which already appeared in the Econlit search. Table 3 presents a complete list of the full sample of 78 papers.

Estimates from non-log specifications and extreme outliers were also deleted. We eliminated 9 estimates from levels specifications and 5 from semi-log specifications since they cannot be directly compared with the elasticities given by the log-log specification. We also removed some outliers. Extreme deviations from the main sample of estimates are problematic for both our graphical and statistical analyses. In the former, they compress the variation of the rest of the sample and in the latter, they are likely to lead to fragile findings. The decision of which observations to define as outliers and removed requires a numerical cut-off. We em- 
ploy the Grubbs test (NIST/SEMATECH, 2004) as our criterion. This test calculates, $G$, the maximum deviation from the sample mean, $\bar{x}$, divided by the standard deviation, $s$, calculated including that observation. If $G=\max \left\{\left|x_{i}-\bar{x}\right| / s\right\}>G^{*}$, the observation is deleted. The critical value for $G$ for confidence level $\alpha$ is given by $G^{*}=(N-1) \sqrt{t^{2} /\left[N\left(N-2+t^{2}\right)\right.}$, where $t$ is the critical value of a t-distribution with $N-2$ degrees of freedom and a confidence interval of $\alpha /(2 N)$. We start with $N=1060$ observations and set $\alpha=.05$, yielding $G^{*}=4.05$. The Grubbs procedure eliminates one outlier at a time, recalculating $\bar{x}$ and $s$ with each iteration. Application of this procedure led to the removal of 8 distance coefficients. ${ }^{3}$ This caused the standard deviation of $\hat{\theta}_{i}$ to decline from 1.845 to 0.411 while the mean hardly changed $(0.933$ vs. 0.893).

After the above deletions, the 78 studies provide 1052 usable observations. They span a relatively large period going from 1870 to 1999, including 137 pre-1970 sample estimates. Different observations from the same paper are not likely to be independent. Concern over lack of independence causes some authors to reduce their sample to a single observation per paper. This approach is usually inappropriate for three reasons. First, it is inefficient to discard information. Second, it is not clear which estimate one should use. Third-and most importantly for our purposes - different estimates often differ in terms of sample period, method, etc. and therefore within-study variation among distance effect estimates can be used to assess the importance of such variables. We consider estimates from the same study as distinct - but possibly correlated - observations in most of our statistical analyses.

The estimated distance coefficients $\left(-\hat{\theta}_{i}\right)$ range from 0.043 to -2.326 , with 1051 estimatesall except one - of a negative effect of distance on bilateral trade. The mean distance effect is 0.893 and the median is $0.850 .{ }^{4}$ Taking a simple mean does not make use of any information on the precision of each estimate. A minimum variance estimate of the mean weights each individual estimate by the inverse of its variance. We consider two possible variance estimates.

\footnotetext{
${ }^{3}$ The eliminated observations were $51.71,-26.68,7.28,6.53,2.84,2.8,2.63$, and 2.62 . With a $1 \%$ confidence level, 2.63 and 2.62 would have been retained. Use of a $10 \%$ confidence level deletes the same values as the $5 \%$ level. A Stata program is available from the authors.

${ }^{4}$ Thus more than half of the sample lies below the interval suggested by Overman et al. (2003).
} 


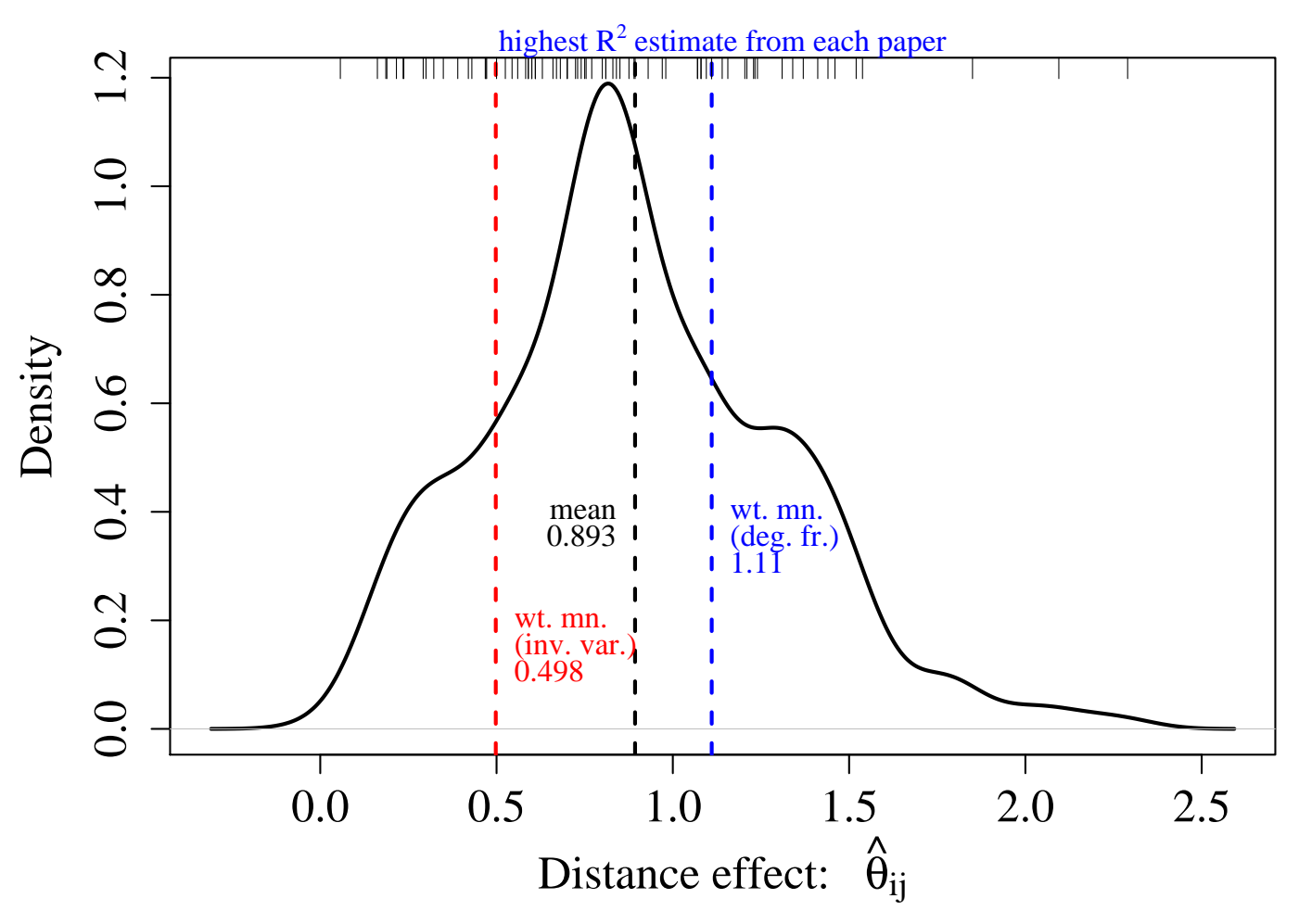

Figure 1: Estimated density of the $1052 \hat{\theta}$ estimates

First, 970 estimates have associated standard errors, denoted s.e. $\left(\hat{\theta}_{i}\right)$. Thus, one possible weight would be $\omega_{i}=1 /$ s.e. $\left(\hat{\theta}_{i}\right)^{2}$. Certain econometric methods underestimate standard errors, often by ignoring correlations between observations in a panel data set or imposing other unduely restrictive assumptions on the variance-covariance matrix. A second possible way to weight observations is to use degrees of freedom. Other things equal, the standard error of $\hat{\theta}$ should be inversely proportional to the square root of the degrees of freedom. One over the variance would therefore be proportional to the degrees of freedom.

Figure 1 provides the kernel density estimates. The vertical lines provide the arithmetic mean as well as two possible minimum variance weighted means. Note that the first, weighting by $\omega_{i}=1 /$ s.e. $\left(\hat{\theta}_{i}\right)^{2}$, is very low. This arises mainly from a single study that reports extremely low standard errors. This might be attributable to the quasi-maximum likelihood method employed. After squaring these small numbers, the weight on their low $\hat{\theta}_{\mathrm{s}}$ rises dramatically. The degrees of freedom weighting, $\omega_{i}=n_{i}-k_{i}$, seems more robust to differences in econometric 
method. Therefore, we regard 1.11 as the preferred estimate of the mean distance effect.

The "best" estimates from each paper-as measured by the $R^{2}$ of the corresponding regression - are depicted graphically in figure 1 using short vertical lines arrayed along the top side of the figure. These estimates average 0.79 . We will return to these best estimates when we consider the possibility of publication bias in section 6 .

\section{Why Distance Effects Vary}

Here we provide a generic classification of the reasons why we should expect different studies and different specifications within studies to generate different estimates.

"sampling" variation: random error in estimating a population parameter due to use of data from a finite sample drawn from that population.

"structural" variation: differences in parameters across sub-populations of the data.

"method" variation: differences in statistical technique lead to different estimates. This includes biases away from the true value caused due to mis-measurement of the explanatory variable or omission of important control variables.

As we shall describe below we introduce a number of explanatory variables to quantify the importance of each source of variation in estimated distance effects.

\subsection{Sampling variation}

Distance coefficients are usually based on a sample of countries and years. Even if all samples were drawn from a population with the same underlying distance effect, regression estimates of the distance effect would differ from the true population mean by an amount referred to as sampling error.

Let $\hat{\theta}_{i}$ represent an individual estimate of the distance effect and $\bar{\theta}$ be an estimate of the population mean. Define $z_{i} \equiv\left(\hat{\theta}_{i}-\bar{\theta}\right) /$ s.e. $\left(\hat{\theta}_{i}\right)$. Under the null of a single population 


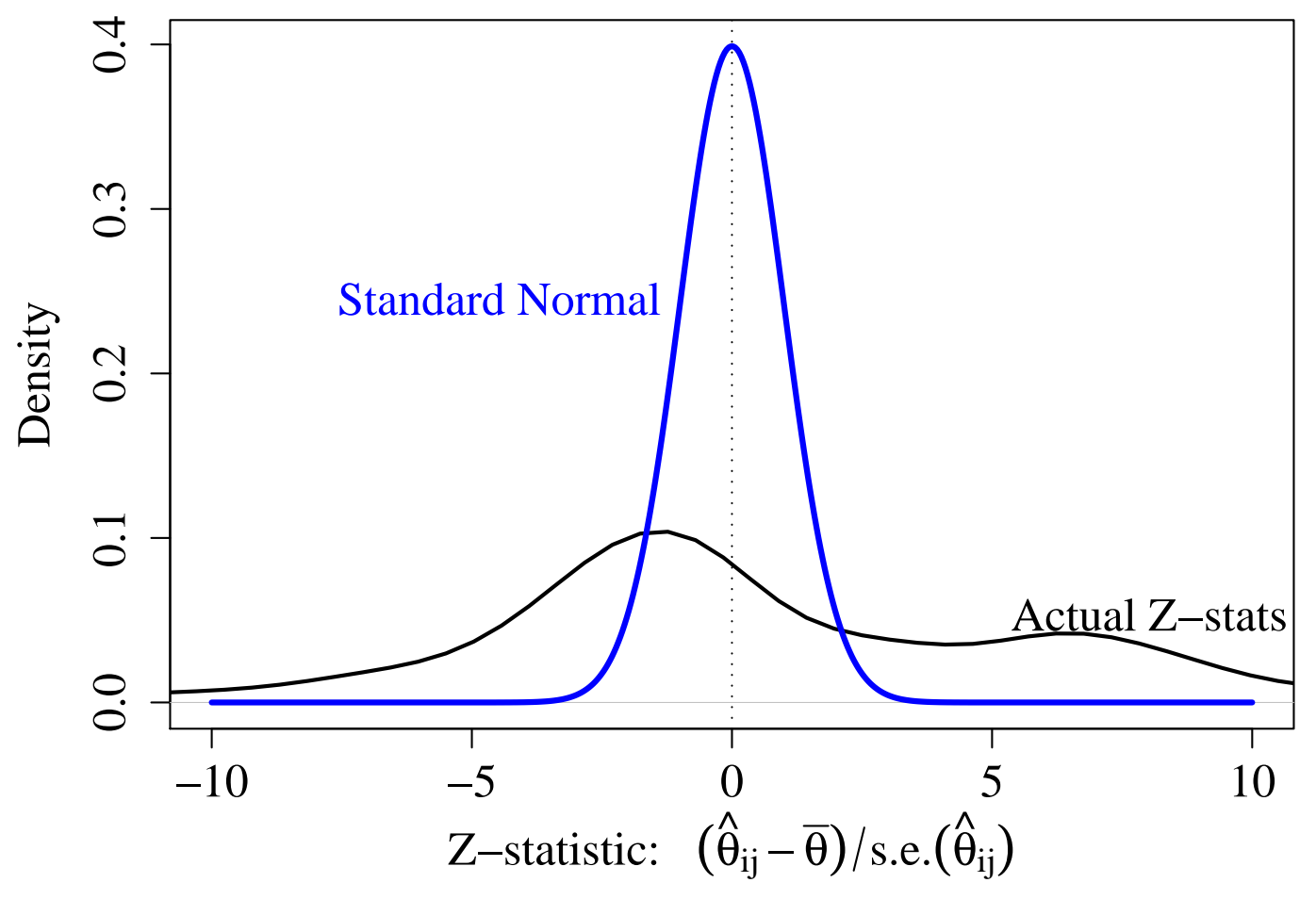

Figure 2: Excess dispersion of $z_{i}$ relative to the standard normal.

mean, $z_{i}$ should be follow a $t$ distribution with $n_{i}-k_{i}$ degrees of freedom. In our database, $n_{i}-k_{i}$ is always 36 or higher, with a median of 1018. With these degrees of freedom, the t-distribution closely resembles the standard normal. Hence we graph $z_{i}$ with the standard normal as benchmark for the case of a common population parameter.

Figure 2 reveals that sampling error can only explain a small portion of the variance in the $\hat{\theta}_{i}$.

\subsection{Structural variation}

Gravity equations have been estimated for heterogeneous sets of countries and industries. It seems likely that different "sub-populations" will have different distance effects. In this subsection we provide a derivation of the gravity equation that allows how to see what underlying structural parameters determine the distance effect.

While the theoretical basis for gravity equations initially amounted to "hand-waving" 
intuitions, we now know that the key underlying assumption is a constant elasticity demand curve for products manufactured in different countries. Here we move quickly through the derivation, using a specification general enough to encompass monopolistic competition and Armington assumptions.

$$
x_{i j}=\frac{n_{i}\left(p_{i j} / \nu_{i j}\right)^{1-\sigma}}{\sum_{k} n_{k}\left(p_{k j} / \nu_{k j}\right)^{1-\sigma}} Y_{j} .
$$

The prices $p_{i j}$ are the prices paid by consumers in market $j$. These consumers "adjust" prices in their utility functions based on their perceptions of the non-pecuniary aspects of products from country $i$, denoted $\nu_{i j}$. Thus the quality-adjusted price is a bilateral variable defined by the ratio $p_{i j} / \nu_{i j}$. There are $n_{i}$ varieties produced by each exporter $i$ viewed by consumers as symmetrically differentiated with elasticity $\sigma$.

The relationship between factory gate $\left(\mathrm{EXW}, p_{i}\right)$ prices in country $i$ and the delivered (DDP,$\left.p_{i j}\right)$ prices in country $j$ are given by

$$
p_{i j}=p_{i} \alpha_{i j} D_{i j}^{\delta_{p}}
$$

where the pecuniary costs related to distance (namely, freight and insurance) are captured in parameter $\delta_{p}$ (the elasticity of transport costs with respect to distance).

The relationship between non-pecuniary aspects of a good as perceived in the destination and origin nations is given by an analogous equation:

$$
\nu_{i j}=\nu_{i} \beta_{i j} D_{i j}^{\delta_{\nu}}
$$

In this formulation $\delta_{\nu}$ includes the effect of passage of time en route on the value of good (perishability, inventory management costs, etc.). It also captures distance-related search costs (see Rauch, 1999).

Substituting in these equations, taking logs, and incorporating some abbreviations, we 
obtain

$$
\ln x_{i j}=\ln n_{i}-(\sigma-1) \ln \left(p_{i} / \nu_{i}\right)+\ln Y_{j}-\ln \left(\sum_{k} n_{k}\left(p_{k j} / \nu_{k j}\right)^{1-\sigma}\right)-\theta \ln D_{i j}+\epsilon_{i j}
$$

where $\epsilon_{i j}=-(\sigma-1)\left(\ln \alpha_{i j}+\ln \beta_{i j}\right)$ is an error term and $\theta=(\sigma-1)\left(\delta_{p}+\delta_{\nu}\right)$ shows the

structural parameters behind the distance effect. The key take-away from this expression is that $\theta$ is not just a measure of transport costs. Rather, the distance effect depends on the elasticity of substitution between varieties, the pecuniary and non-pecuniary effects of distance on "quality-adjusted" delivered prices. Cross-sample variation in any of these three structural parameters would be expected to lead to cross-sample variation in the estimated distance effect.

Our database shows that estimations based on former time periods are mainly intercontinental whereas those based on more recent time periods study also quite often trade flows between intra-continental countries. To control for a possible relation between the magnitude of the distance effect on trade and the distance between the trade partners, we introduce a dummy "single continent" to take account of whether the countries are on the same continent or not. There are also dummies for whether the estimation includes only developed economies, only developing and/or transition countries, or a mix of both groups. We expect lower distance effects for developed economies because of superior transport infrastructure (low $\delta_{p}$ ) and greater tendency to trade differentiated products (low $\sigma$ ). On the other hand, higher valuations of time (high $\delta_{\nu}$, perhaps because of the use of Just-in-time) would offset these two effects. Furthermore, we include a dummy to take into account the level of aggregation of data (aggregated vs. disaggregated), since it seems likely that disaggregated categories exhibit more substitutability and therefore, other things equal, larger distance effects.

\subsection{Method variation}

Meta-analysis of distance effects is made easier by the general consensus that the gravity equation is the appropriate method. This yields a linear in logs functional form that facilitates 
comparison of results because we are always considering elasticities. Even though almost all studies use the log-log specification, there are differences across studies in measuring bilateral trade flows. Some studies sum imports and exports for a given country pair whereas other studies focus on directional trade (either imports or exports). The latter seems to be the method indicated by the theory but the former is also frequently used. We take account of differences in the definitions of the dependent variable by including a dummy to control for whether the dependent variable used is total bilateral trade flows or only bilateral import or export flows.

Most of the papers calculate distances using the great-circle formula. This is appealing because it requires only the latitude and longitude of principal cities for each country. Only in the case of air transport do great-circle routes correspond closely to actual cargo routes (and there are exceptions for air routes as well). A small number of authors have taken the trouble to determine actual distances traveled by road or sea. We use a dummy to test the hypothesis that this improvement in measurement should increase the estimated distance effect.

Many studies omit variables that are (i) important determinants of trade and (ii) correlated with distance. This induces omitted variable bias in the estimated distance effects from those studies. Key variables to consider here are adjacency (strongly related to distance), language, preferential trade agreements (often of a regional nature), and remoteness.

We consider four dummies that each takes a value of 1 if the underlying estimation controls respectively for the adjacency, the sharing of a language, the belonging to the same preferential trade agreement (PTA), and includes a measure of remoteness. However, the control for common language or membership of a preferential trade area is not relevant for some observations (e.g. observations studying only trade flows between Canada and United States). Note that the dummies take a value of 1 for theses observations because we wish to interpret a zero as reflecting a failure to control for an important variable when necessary.

Another econometric problems researchers occasionally address in gravity equations is the possible endogeneity of the GDP terms. This could cause simultaneity bias that might feed into bias in distance effects. We include a dummy that equals one if the author(s) $\operatorname{control}(\mathrm{s})$ 
for the potential correlation between the GDP regressor and the errors terms.

While most large countries trade with each other, there are some country pairs with zero trade, especially in disaggregated industries. Discarding these zeros would result in selection bias that again might have an effect on distance effects. We code a dummy which takes a value 1 if the estimation includes the zero flows or if there are no zero flows to be included. Finally, we control for the quality of the publication by adding a dummy equals to 1 if the study was published in the American Economic Review, the Journal of International Economics or the Review of Economics and Statistics.

Table 1 summarizes the meta-independent variables and presents the mean for each subperiod. A few trends seem noteworthy. First, the distance effect is much smaller before 1970. Second, studies looking at trade within a continent tend to use more recent data. It seems

likely that this accounts for the rise in the share of developed countries only in later samples. Third, authors using recent data are more likely to control for remoteness. Finally, studies of recent sample periods tend to distinguish between export and import flows rather than summing them.

\section{Meta-regressions results}

In this section, we present the empirical results for the meta-regression analysis. All studies in our sample, except one, report more than one estimate. The presence of multiple estimates per study remains a disputed issue in meta-analysis. Clearly, one cannot assume that multiple observations from the same study are independent draws. Furthermore, when the number of estimates per study differs, counting all estimates equally would tend to overweight studies with many estimates (Stanley, 2001). Various solutions have been suggested in the literature on meta-analysis to tackle this problem: represent each study with a single observation, include a dummy variable (fixed effect) for each study that provided more than one observation (Jarrell and Stanley, 1990), use a panel specification (Jeppesen et al., 2002).

Using a single observation raises the question of which one. Some meta-analyses (e.g. 
Table 1: Descriptive statistics

\begin{tabular}{||l|c|c|c|c||}
\hline \hline \multicolumn{1}{|c|}{ Name } & \multicolumn{3}{|c||}{ Mean } \\
& $\leq \mathbf{1 9 6 9}$ & $\mathbf{1 9 7 0 s}$ & $\mathbf{1 9 8 0}$ & $\mathbf{1 9 9 0}$ \\
\hline Dependent variable & & & & \\
Distance Effect (- elasticity of trade w.r.t. dist.) & 0.645 & 0.881 & 0.935 & 0.941 \\
Structural variables & & & & \\
Average Year (Midpoint of estimation period) & 1943.15 & 1974.28 & 1984.94 & 1992.85 \\
Single Continent & 0.204 & 0.200 & 0.314 & 0.334 \\
Developed Economies Only & 0.394 & 0.452 & 0.439 & 0.546 \\
No Developed Economies & 0.000 & 0.111 & 0.050 & 0.034 \\
Disaggregated Data & 0.248 & 0.407 & 0.161 & 0.442 \\
Method Variables & & & & \\
Total Bil. Trade (sum of two-way trade flows) & 0.401 & 0.326 & 0.393 & 0.242 \\
Road/Sea distance & 0.175 & 0.281 & 0.150 & 0.168 \\
Adjacency Control & 0.723 & 0.756 & 0.471 & 0.456 \\
Common Lang. Control & 0.175 & 0.459 & 0.539 & 0.450 \\
Trade Agreements Control & 0.883 & 0.911 & 0.729 & 0.640 \\
Remoteness Control & 0.007 & 0.185 & 0.268 & 0.286 \\
GDP Endogeneity Correction & 0.095 & 0.007 & 0.146 & 0.128 \\
Incorporates Zero Flows & 0.766 & 0.607 & 0.625 & 0.404 \\
High Quality Review & 0.496 & 0.496 & 0.232 & 0.310 \\
\hline \hline
\end{tabular}


Card and Krueger, 1995) identify a "preferred" estimate, others use averages or medians of the estimates from each paper and some even randomly select one estimate (Stanley, 2001, Rose, 2004). Bijmolt and Pieters (2001) show that the procedures using a single value for each study generate misleading results. In our study we would lose valuable information from studies that estimate gravity equations for multiple years.

The use of dummies for study fixed effects forces the regression to identify all relationships based on within-study variation. This prevents meta-analysis from achieving its main function: the combination of information from multiple studies. Therefore, to deal with the problem of dependence, we adopt the panel specification with random effects suggested by Jeppensen et al. (2002). The estimated model could be expressed as follows:

$$
\hat{\theta}_{i j}=u_{i}+\beta X_{i j}+e_{i j}
$$

Where $\hat{\theta}_{i j}$ is the $j$ th distance coefficient reported in study $i, X_{i j}$ is the matrix of the metaindependent variables included to explain the estimation-to-estimation variation of the distance elasticities, and $\beta$ the meta-regression coefficients. The $u_{i}$ are the "random study" effects. $^{5}$

Results are reported in table 2. The plan of the table is to take a first pass at establishing the time trend in distance coefficients (columns 1 and 2 and Figure 3). Then we will add "structural" variables (column 3) and method variables (column 4) to assess whether these controls change the results. The last column focuses on the question of whether estimates from Econlit sample give different results. The last 4 rows of the table present measures of the overall fit of the regression. There are two dimensions of variation, between and within studies. Recall that the error associated with the former is $u_{i}$ and the latter is $e_{i j}$.

Specification (1) regresses the distance estimates solely on the midyear of each sample. We subtract 1870 from this variable so that the constant can be interpreted as the distance

\footnotetext{
${ }^{5}$ Jeppesen et al. (2002) use the expression "random researcher" effects for $u_{i}$. But, as our database includes papers written by the same author(s), we prefer the alternative expression "random study" effect. We also experimented with dummies for authors with multiple papers. The coefficients were mainly insignificant and did not affect the $\beta$ s in any noteworthy ways.
} 
Table 2: Meta-Regression Results - Random Effect

\begin{tabular}{|c|c|c|c|c|c|}
\hline Specification: & (1) & $\overline{(2)}$ & $2(3)$ & (4) & $(5)$ \\
\hline Sample: & All & All & All & All & Econlit \\
\hline \# of Obs.: & 1052 & 1052 & 1052 & 1052 & 774 \\
\hline Intercept & $\begin{array}{l}0.55^{a} \\
(0.12)\end{array}$ & $\begin{array}{l}0.74^{a} \\
(0.05)\end{array}$ & $\begin{array}{l}0.64^{a} \\
(0.06)\end{array}$ & $\begin{array}{l}0.66^{a} \\
(0.08)\end{array}$ & $\begin{array}{l}0.64^{a} \\
(0.09)\end{array}$ \\
\hline Average Year of Sample - 1870 & $\begin{array}{l}0.003^{a} \\
(0.001)\end{array}$ & & & & \\
\hline $1970 \leq$ Av. Year $\geq 1979$ & & $\begin{array}{l}0.13^{a} \\
(0.04)\end{array}$ & $\begin{array}{l}0.12^{a} \\
(0.04)\end{array}$ & $\begin{array}{l}0.12^{a} \\
(0.04)\end{array}$ & $\begin{array}{l}0.08^{c} \\
(0.04)\end{array}$ \\
\hline $1980 \leq$ Av. Year $\geq 1989$ & & $\begin{array}{l}0.17^{a} \\
(0.04)\end{array}$ & $\begin{array}{l}0.16^{a} \\
(0.04)\end{array}$ & $\begin{array}{l}0.15^{a} \\
(0.04)\end{array}$ & $\begin{array}{l}0.15^{a} \\
(0.05)\end{array}$ \\
\hline $1990 \leq$ Av. Year $\geq 1999$ & & $\begin{array}{l}0.18^{a} \\
(0.05)\end{array}$ & $\begin{array}{l}0.17^{a} \\
(0.04)\end{array}$ & $\begin{array}{l}0.16^{a} \\
(0.04)\end{array}$ & $\begin{array}{l}0.19^{a} \\
(0.05)\end{array}$ \\
\hline Single Continent & & & $\begin{array}{l}0.41^{a} \\
(0.06)\end{array}$ & $\begin{array}{l}0.32^{a} \\
(0.07)\end{array}$ & $\begin{array}{l}0.32^{a} \\
(0.08)\end{array}$ \\
\hline Developed Economies Only & & & $\begin{array}{r}-0.10^{b} \\
(0.05)\end{array}$ & $\begin{array}{r}-0.11^{b} \\
(0.05)\end{array}$ & $\begin{array}{l}-0.10^{c} \\
(0.05)\end{array}$ \\
\hline No Developed Economies & & & $\begin{array}{l}0.18^{b} \\
(0.07)\end{array}$ & $\begin{array}{l}0.19^{a} \\
(0.07)\end{array}$ & $\begin{array}{l}0.22^{a} \\
(0.08)\end{array}$ \\
\hline Disaggregate Data & & & $\begin{array}{c}0.14^{b} \\
(0.06)\end{array}$ & $\begin{array}{c}0.14^{b} \\
(0.06)\end{array}$ & $\begin{array}{l}0.28^{a} \\
(0.07)\end{array}$ \\
\hline Total Bilateral Trade & & & & $\begin{array}{l}-0.05 \\
(0.06)\end{array}$ & $\begin{array}{l}-0.08 \\
(0.06)\end{array}$ \\
\hline Road/Sea Distance & & & & $\begin{array}{l}-0.02 \\
(0.11)\end{array}$ & $\begin{array}{c}0.05 \\
(0.13)\end{array}$ \\
\hline Adjacency Control & & & & $\begin{array}{l}-0.16^{a} \\
(0.03)\end{array}$ & $\begin{array}{l}-0.17^{a} \\
(0.03)\end{array}$ \\
\hline Common Language Control & & & & $\begin{array}{l}0.12^{a} \\
(0.04)\end{array}$ & $\begin{array}{l}0.13^{a} \\
(0.05)\end{array}$ \\
\hline Trade Agreements Control & & & & $\begin{array}{l}-0.02 \\
(0.03)\end{array}$ & $\begin{array}{l}-0.02 \\
(0.04)\end{array}$ \\
\hline Remoteness Control & & & & $\begin{array}{l}0.001 \\
(0.04)\end{array}$ & $\begin{array}{l}-0.01 \\
(0.04)\end{array}$ \\
\hline GDP Endogeneity Correction & & & & $\begin{array}{r}-0.004 \\
(0.03)\end{array}$ & $\begin{array}{l}-0.02 \\
(0.04)\end{array}$ \\
\hline Incorporates Zero Flows & & & & $\begin{array}{l}0.07^{b} \\
(0.03)\end{array}$ & $\begin{array}{c}0.03 \\
(0.04)\end{array}$ \\
\hline High Quality Review & & & & $\begin{array}{c}0.10 \\
(0.08)\end{array}$ & $\begin{array}{r}0.03 \\
(0.16) \\
\end{array}$ \\
\hline$R^{2}$ between & 0.044 & 0.071 & 0.139 & 0.130 & 0.172 \\
\hline$R^{2}$ within & 0.006 & 0.012 & 0.073 & 0.111 & 0.149 \\
\hline Std. error of $u_{i}$ & 0.338 & 0.338 & 0.327 & 0.340 & 0.372 \\
\hline Std. error of $e_{i j}$ & 0.210 & 0.210 & 0.203 & 0.200 & 0.205 \\
\hline
\end{tabular}

Note: Standard errors in parentheses with ${ }^{a},{ }^{b}$ and ${ }^{c}$ respectively denoting significance at the $1 \%, 5 \%$ and $10 \%$ levels. 


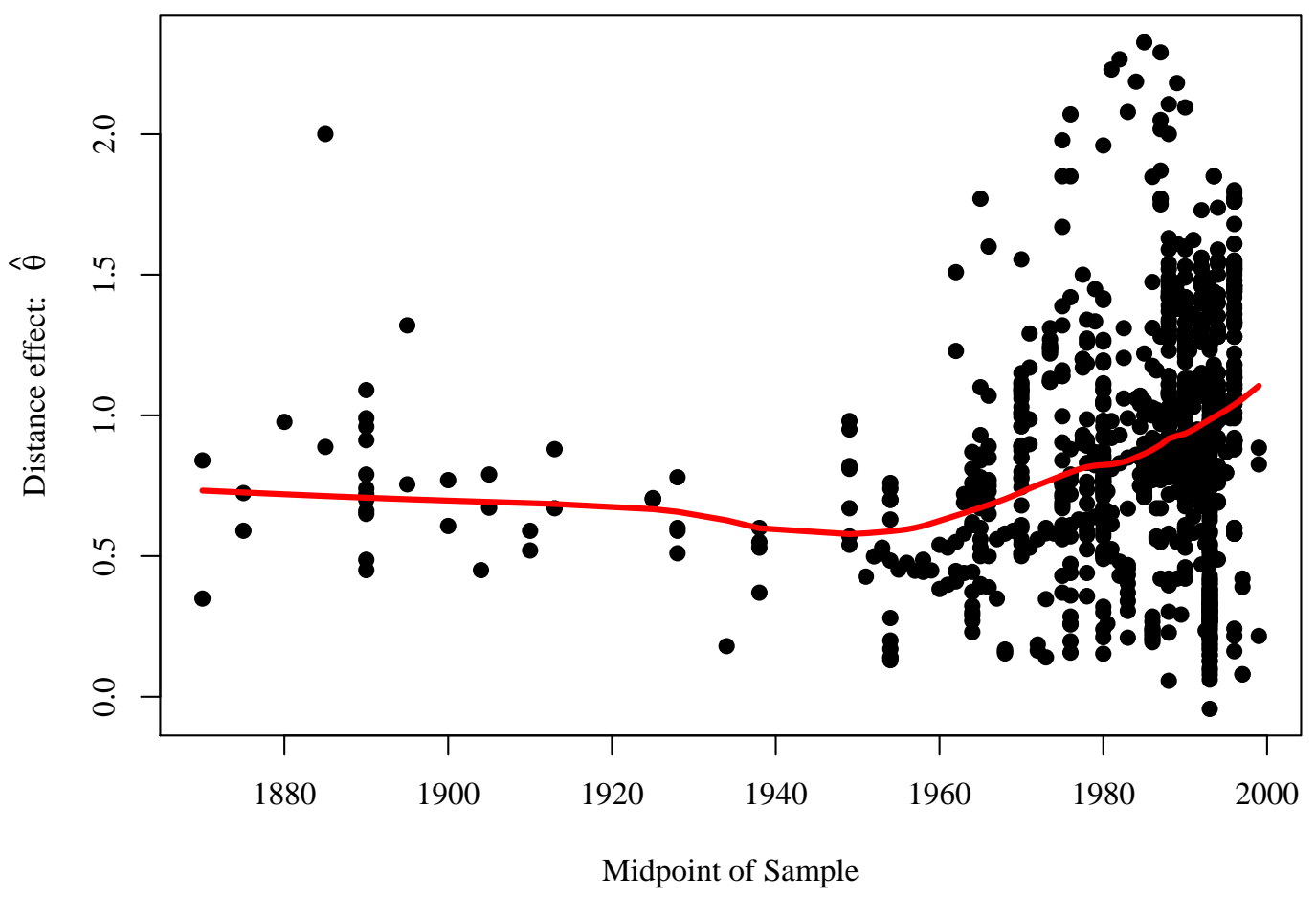

Figure 3: The variation of $\hat{\theta}$ graphed relative to the mid-period of the data sample.

effect for the earliest observation of the dataset. The estimated coefficient on the average year is positive and significant at the $1 \%$ level. Therefore, the negative impact of distance on trade seems to be rising over time, rather than falling as the conventional wisdom would have suggested.

The linear specification of column (1) is a strong assumption to impose on estimates spanning 130 years. Figure 3 graphs the estimates against time and fits a kernel smoother through the data. The relationship between distance effects and sample period seems fairly flat until the 1950s. We therefore estimate the rest of our regressions with a more flexible form based on dummies for 4 period ranges: before 1970, the 70s, the 80s, and the 90s. Column (2) provides the results for this specification. It shows a fairly steady increase in the distance effect. Indeed distance impedes trade by $24 \%$ more - $(0.18 / 0.74)$ - in the 1990 s than it did from 1870 to 1969 ! This change is statistically different from 0 at the $1 \%$ significance level.

A critical question is whether distance really matters more in later periods or whether 
there are systematic differences in the attributes of studies that lead to higher estimates. Columns (3) and (4) control for aspects of the estimates that could matter.

The first set of controls - shown in column (3) - are what we term "structural" variables. The coefficient on the variable "single continent" is positive and significant at the $1 \%$ level. Given that intra-continental trade is much more likely to involve land transport, this suggests a higher transport elasticity $\left(\delta_{p}\right)$ for land trade. It might also suggest that the shorter is the distance between trade partners, the greater is distance effect on trade. Our results on the geographic dummies are relatively intuitive. We find a significant and positive coefficient on the dummies for samples that do not include developed countries, while the coefficient on developed countries is negative. A higher distance effect for samples of poorer economies is consistent with their less developed transportation infrastructure causing a higher $\delta_{p}$. The coefficient on disaggregated data suggests that estimations based on disaggregated data may obtain a higher distance effect than estimations conducted with aggregated data. This makes sense if one thinks of disaggregated industries as having larger elasticities of substitution $(\sigma)$. These results corroborate results from Hummels (1999) where, using very different data, he finds evidence of large $\delta_{p}$ for land transport and poor countries as well as some suggestive data supporting large $\sigma$ for disaggregated goods.

Column (4) introduces nine "method" variables that consider issues such as measurement of the key variables, the set of controls, the set of econometric "corrections", and journal quality. Estimations relating bilateral trade flows (exports plus imports) to income, distance and dummy variables tend to have a similar distance effect as estimations using bilateral import or export flows. The distance coefficient is hardly affected by the use of distances by road or by sea. This is very surprising since great circle distances disregard so much about the actual geography of transportation. Perhaps it is reassuring to all who have relied on the great circle distances because they wanted to avoid the task of collecting actual distances traveled.

Our next results suggest that omitted variable bias can have significant impacts on estimated distance effects. In particular a failure to include a dummy for adjacent country 
pairs seems to cause an overestimate of the distance effect. This makes sense since adjacency is likely to be negatively correlated with distance, leading to upward omitted variable bias (on the distance effect - the bias on the negative distance coefficient would be downward). It is not clear why adjacency should matter after controlling for distance. Head and Mayer (2002) argue that estimated adjacency effects arise mainly because center-to-center distances underestimate distance effect between nearby countries. Another important control is for a common language. Here the correlation with distance is not obvious. Some pairs like Belgium and France, Ireland and the U.K., are relatively proximate whereas country pairs that share a language due to colonization patterns (U.K. and Australia, say) are very far apart. The results suggest that the latter set of countries dominate: the inclusion of the common language control significantly raises the distance effect.

Two other controls that one would expect to matter have a negligible impact. Controlling for membership of a preferential trade agreement has a small and insignificant effect. Distance effects on trade also seem to be insensitive to the introduction of a "remoteness" control variables. This might be because many of the remoteness variables that have been used do not use functional forms that correspond to the underlying theory. ${ }^{6}$ It also appears that using instruments to control for the endogeneity of GDP has little impact on the distance effect. Column (4) does suggest that including zeros will increase the estimate distance effect by a small amount (.07). Finally, the distance effect does not seem to be affected by the journal quality.

Recall that we constructed our sample by combining estimates from papers found through an Econlit search with papers found through a more focussed search within specific journals. The Econlit sample may be seen as more objective since we exercised more discretion in selecting the remaining papers. Hence we report results in column (5) of Table 2 for the Econlit sample. Although this drops about one quarter of the estimates, the results are quite similar. One notable difference is that the rise in the distance effect only becomes highly significant starting in the 1980s. A second change is that the correction for zeros no longer

\footnotetext{
${ }^{6}$ See Anderson and van Wincoop's (2003) for more on this issue.
} 
seems to affect the distance effect. We found this surprising and investigated whether the particular method for dealing with zeros matters. In unreported results we found that Tobit and Heckman methods tended to yield considerably larger estimates, corroborating Overman et al.'s (2003) observation that "The difference in estimated [distance] coefficients arises, at least in part, because of the treatment of zeros. Tobit estimation typically yields larger coefficients." 7

After controlling between and within-study differences in sample composition, controls, and methods, we find that the basic message of figure 3 remains intact: distance effects are not diminishing over time and in most specifications they seem to be rising. This finding reinforces the puzzle of how to reconcile technology driven reductions in trade costs with a non-shrinking effect of distance. We see three candidate resolutions. First, technological progress may have been smaller or less ubiquitous than casual empiricism would suggest. In particular, advances like email and teleconferencing may not radically alter the marginal cost of distance for trade in goods. Hummels (2000) argues that the data show no decline in transport costs in recent decades. Second, the costs of distance other than the amounts paid to shippers (denoted $\delta_{\nu}$ in the model) may be increasing. Hummels (2001) and Deardorff (2003) suggest that the influence of time on trade is increasing. Greater use of just-in-time as well as a simple income-driven increase in the value of time could raise distance costs. Finally, changes in the composition of trade might be biased towards goods with high distance costs. However, Berthelon and Freund (2004) find that compositional changes had almost no impact on the distance effect.

\section{Publication bias}

A persistent concern in all literature reviews, is that the publication process may have influenced the set of findings available to be assessed. To the extent that referees and editors of academic journals insist upon statistically significant results, the published sample of re-

\footnotetext{
${ }^{7}$ The standard errors on these method indicators were large and the effects of the different methods depends on the sample. In the complete sample of column (4), only the Heckman procedure had a significant effect.
} 
sults will differ systematically from the full set of estimates. Fortunately, researchers using meta-analysis have developed tests to uncover the presence of publication bias.

We use two methods proposed by Card and Krueger (1995) in a meta-analysis of the employment effects of minimum wages. Since all the estimates in a given paper are either published or not, it does not make much sense to consider publication bias at the level of individual estimates. For this reason we follow Card and Krueger's (1995) practice of reducing the sample to one $\hat{\theta}_{i}$ estimate per paper. Card and Krueger selected a "preferred estimate" for each of the papers in their meta-analysis. In our sample it is often infeasible to determine a single estimate preferred by the authors. We opt instead to select the "best" estimate from each paper using a quantitative criterion: the highest $R^{2}$ for the corresponding regression. For the two papers that did not report $R^{2}$, we used the last estimate of each paper.

The first method consists of a regression of the log of the t-statistic on the distance coefficient on the log of the square root of the degrees of freedom. Suppose that the size of the sample is determined exogenously by data availability. Then, sampling theory predicts that the absolute value of the t-statistic should be proportional to the square root of the degrees of freedom. In the absence of publication bias we therefore expect a unit value on the estimated elasticity. Some papers which do not report standard errors or t-statistics, and/or sample size are excluded. This leaves us with a sample of 66 papers, 57 of which are published in journals. Using just the latter we find a coefficient of 0.60 with a standard error of 0.16 . Although this is significantly less than one, one should not interpret this as strong evidence for publication bias. The key finding is that increasing sample size does have the large positive effect on significance that sampling theory predicts. In sharp contrast, Card and Krueger (1995) find a negative relationship in their meta-analysis. Görg and Strobl (2001) find a slightly negative correlation in their study of productivity spillovers from multinational corporations (MNCs).

Figure 4 illustrates the 66 studies reporting enough information to calculate t-statistics and degrees of freedom. Note that the 9 book chapters and working papers (depicted using hollow circles) do not appear to have a markedly different pattern than the papers published in journals (shown with solid circles). 


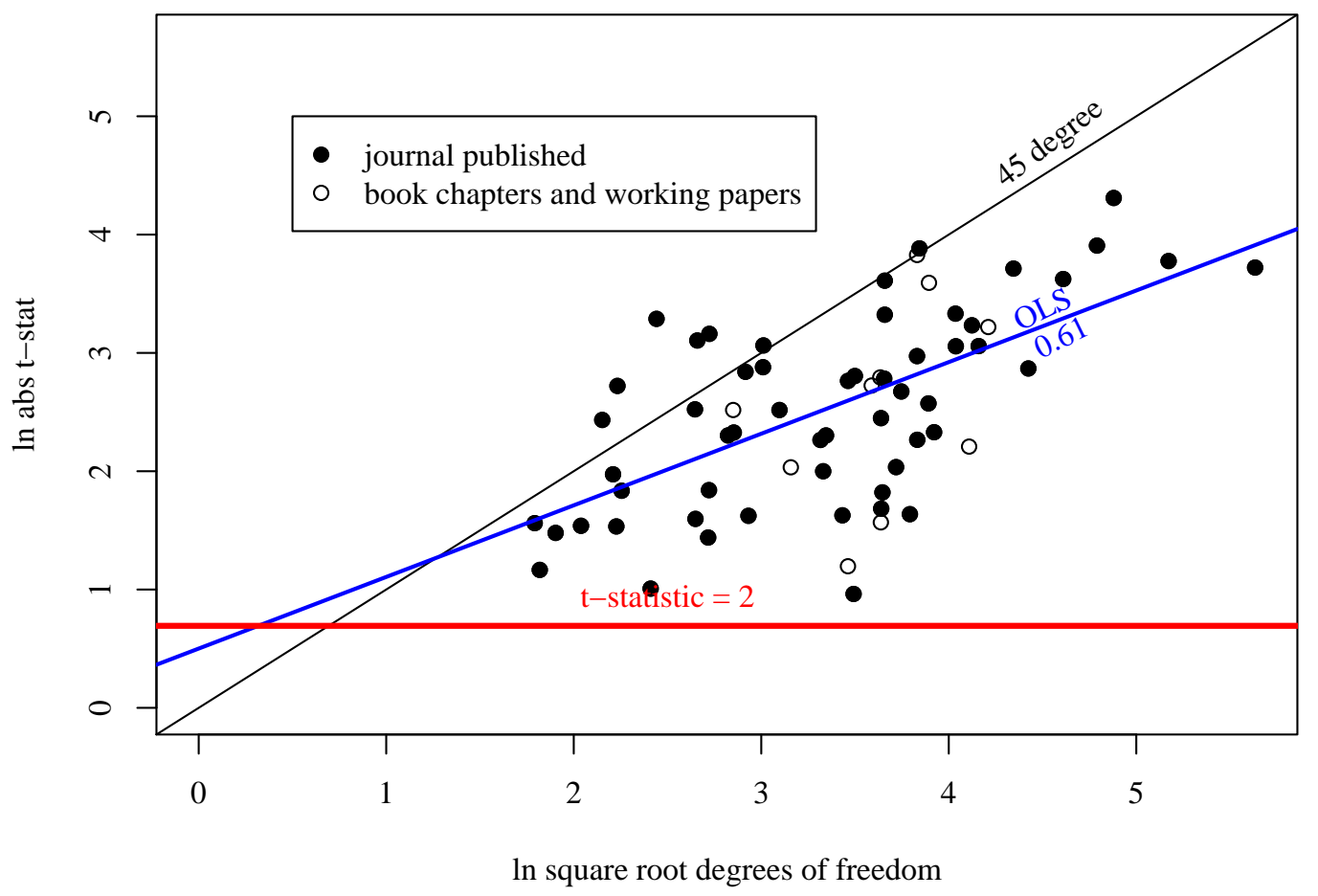

Figure 4: Absolute values of t-statistics rise with the square root of degrees of freedom, but not proportionately

The second method relates the distance coefficients to their standard errors. In the absence of publication bias, we have no reason to expect a relationship between the strength of the distance effect and the precision with which it is measured. However, if the best estimate from a study needs to be statistically significant at conventional levels to be published, then a process of specification searches might lead to coefficients that cluster at or slightly above twice their standard error.

Figure 5 provides a line corresponding to t-statistics of two. We see that most of the data lie well above this line and that there is little apparent relationship between estimates and their standard errors. The correlation for published papers in journals is 0.09. This figure displays six estimates that were not shown in figure 4 because the papers did not report degrees of freedom. All are published in journal and have t-statistics over two. These results contrast sharply with the meta-analyses of Card and Krueger (1995) and Görg and Strobl (2001). The former observe that a line through the origin with a slope of two "fits the data 


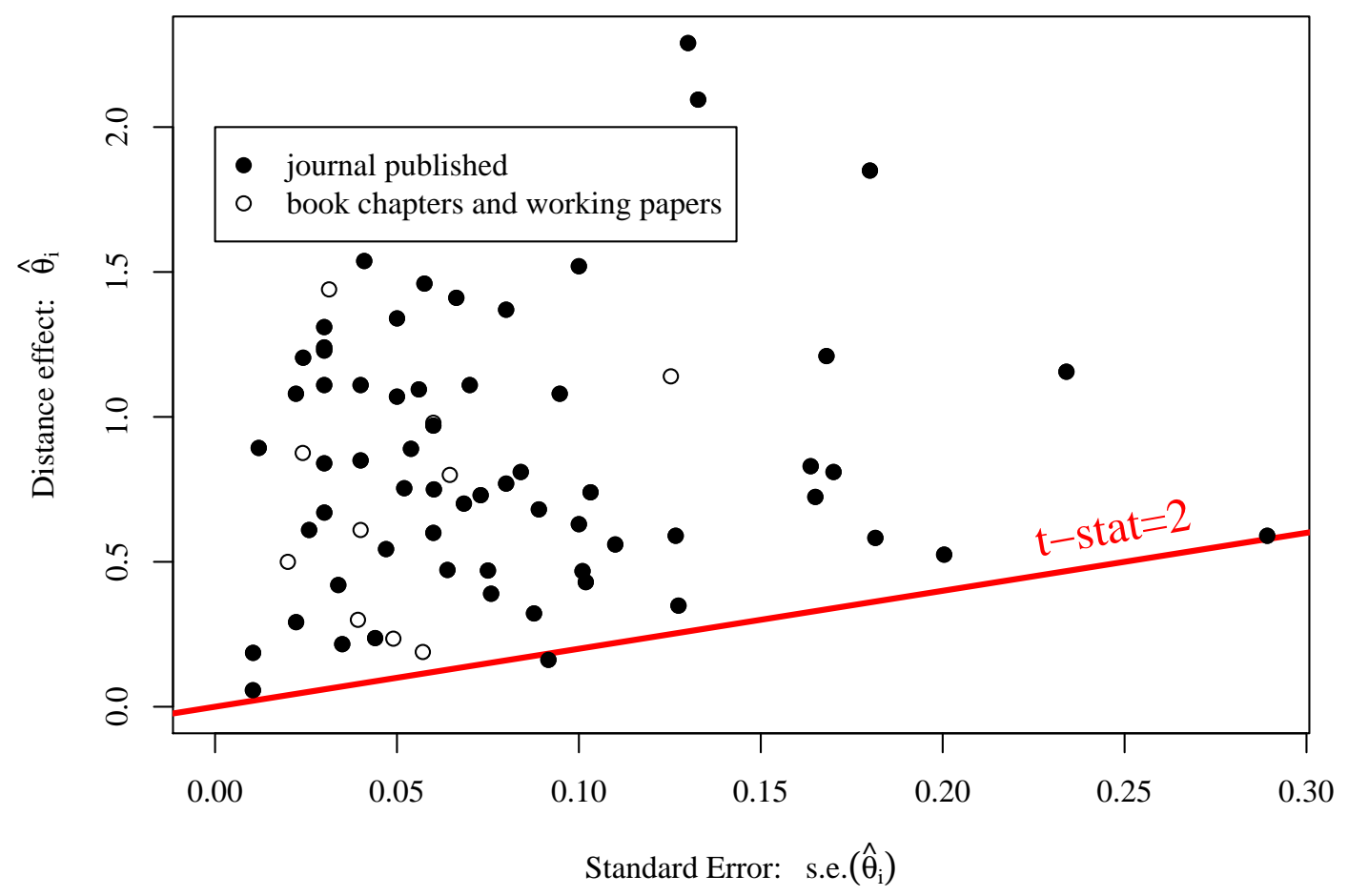

Figure 5: The (non) relationship between coefficients and standard errors

rather well." The latter estimate the relationship, obtaining a coefficient of about three.

In contrast to earlier studies, we find only very weak evidence of publication bias. Perhaps this should not be very surprising since distance is usually just a control variable in studies based on the gravity equation. Hence, publication pressure may have less effect on the distance coefficient than it has on variables of substantial policy interest like minimum wages and MNC spillovers.

\section{Conclusion}

The popularity of the gravity equation for trade has made available hundreds of estimates of the elasticity of bilateral trade with respect to distance. Our paper is the first to collect and systematically analyze these estimates. Our mean across 1052 estimates is 0.89 , a value that is not at all surprising but does lie somewhat above Leamer and Levinsohn's (1995) point 
estimate and at the lower bound of the interval proposed by Overman et al. (2003). We show that there is huge variation in the distance effect and that it cannot be explained by mere sampling error. The explanation we focus on is change over time. Using estimates spanning well over a century we show that distance effects decreased slightly between 1870 and 1950 and then began to rise. The use of a large number of "meta-variables" to control for relevant differences in the regressions producing our estimates does not cause a notable change in the increase in the distance effect. Our estimates represent a challenge for those who believe that technological change has revolutionized the world economy causing the impact of spatial separation to decline or disappear.

\section{References}

Anderson, J.E. And E. VAn Wincoop, 2003, "Gravity With Gravitas: A Solution to the Border Puzzle", American Economic Review, 93(1): 170-192.

van den Bergh, J. And K.J. Button, 1997, "Meta-analysis of Environmental Issues in Regional Urban and Transport Economics", Urban Studies, 34(5-6): 927-944.

Berthelon, M. And C.L. Freund, 2004, "On the Conservation of Distance in International Trade", World Bank, Policy Research Working Paper 3293.

Bijmolt, T.H.A. And R.G.M. Pieters, 2001, "Meta-Analysis in Marketing when Studies Contain Multiple Measurements", Marketing Letters, 12(2): 157-169.

Brun, J-F., C. Carrère, J. de Melo and P. Guillaumont, forthcoming, "Has Distance Died? Evidence from a Panel Gravity Model", World Bank Economic Review.

Button, K.J., 1995, "What Can Meta-analysis Tell Us about the Implications of Transport?", Regional Studies, 29(6): 507-517.

Cairncross, F., 1997, The Death of Distance: How the Communications Revolution will change our Lives, Orion Business Books, London.

Card, D. And A.B. Krueger, 1995, "Time-Series Minimum-Wage Studies: a Metaanalysis", The American Economic Review, 85(2): 238-243.

Carrère C. And M. Schiff, 2004, "On the Geography of Trade: Distance is Alive and Well", World Bank, Policy Research Working Paper 3206.

Coe D.T., A. Subramanian, N.T. Tamirisa and R. Bhavnani, 2002, "The Missing Globalization Puzzle", IMF, Working Paper \# 171. 
DeardorfF, A., 2003, "Time and Trade: The Role of Time in Determining the Structure and Effects of International Trade, with an Application to Japan", in Stern R. M. (ed), Analytical Studies in U.S.-Japan International Economic Relations, Edward Elgar Publishing Inc.

De MooiJ, R. And S. Ederveen, 2003, "Taxation and foreign direct investment. A synthesis of empirical research", International Tax and Public Finance, 10: 673-693.

Florax, R., H. De Groot And R. DE MooiJ, 2002, "Meta-analysis in policy-oriented economic research", CPB, Report \# 1: 21-24.

Glaeser, E.L. And J.E. Kohlhase, 2004, "Cities, Regions and the Decline of Transport Costs", Papers in Regional Science, 83(1): 197-228.

Glass, G.V., B. McGaw And M. Lee Smith, 1981, Meta-analysis in Social Research, Sage Publications, Beverly Hills.

Görg, H. And E. Strobl, 2001, "Multinational Companies and Productivity Spillovers: A Meta-Analysis", The Economic Journal, 111: 723-739.

HeAd, K. AND T. MAYER, 2002, "Illusory Border Effects: Distance mismeasurement inflates estimates of home bias in trade", CEPII Working Paper \# 2002-01.

Hummels, D., 1999, "Toward a Geography of Trade Costs", University of Chicago, mimeo.

Hummels, D., 2000, "Have International Transportation Costs Declined?", Purdue University, mimeo.

Hummels, D., 2001, "Time as a trade barrier", Purdue University, mimeo.

Jarrell, S.B. And T.D. Stanley, 1990, "A Meta-Analysis of the Union-Nonunion Wage Gap", Industrial and Labor Relations Review, 44(1): 54-67.

Jeppesen, T., J.A. List And H. Folmer, 2002, "Environmental Regulations and New Plant Location Decisions: Evidence from a Meta-Analysis", Journal of Regional Science, 42(1): 19-49.

Leamer, E.E. And J. Levinsohn, 1995, "International Trade Theory: The Evidence", in Grossman G. and K. Rogoff (eds), Handbook of International Economics Volume 3, Elsevier, North-Holland.

NIST/SEMATECH, e-Handbook of Statistical Methods, Chapter 1.3.5.17

〈 http://www.itl.nist.gov/div898/handbook/〉, September 2004 download.

Overman H.G., S. Redding and A.J. Venables, 2003, "The Economic Geography of Trade, Production, and Income: A Survey of Empirics", in Kwan-Choi E. and J. Harrigan (eds.), Handbook of International Trade, J. Basil Blackwell.

RAUCH J.E., 1999, "Networks Versus Markets in International Trade", Journal of International Economics, 48: 7-35. 
Rose, A.K., 2004, "The Effect of Common Currencies on Trade: A Meta-Analysis", in Alexander V., Mlitz J., and G. von Furstenberg (eds.), Monetary Unions and Hard Pegs: Effects on Trade, Financial Development, and Stability, Oxford University Press and CEPR.

Stanley, T.D., 1998, "New Wine in Old Bottles: A Meta-Analysis of Ricardian Equivalence", Southern Economic Journal, 64(3): 713-727.

Stanley, T.D., 2001, "Wheat From Chaff: A Meta-Analysis as Quantitative Literature Review", Journal of Economic Perspectives, 15(3): 131-150.

Stanley, T.D. And S.B. Jarrell, 1989, "Meta-Regression Analysis: A Quantitative Method of Literature Surveys", Journal of Economic Surveys, 3(2): 161-170.

Stanley, T.D. And S.B. Jarrell, 1998, "Gender Wage Discrimination Bias? A MetaRegression Analysis", The Journal of Human Resources, 33(4): 947-973. 
Table 3: Papers included in the database

\begin{tabular}{|c|c|c|c|c|}
\hline Authors and References & Time Period & $\begin{array}{l}\text { Nb. of } \\
\text { estimates }\end{array}$ & Ranges & Mean \\
\hline \multicolumn{5}{|c|}{ ECONLIT SAMPLE } \\
\hline \multicolumn{5}{|c|}{ Published studies in academic journals } \\
\hline $\begin{array}{l}\text { Abraham, F.E. et al. (1997) } \\
\text { Weltwirtschaftliches Archiv }\end{array}$ & $1895-1992$ & 4 & {$[0.18 ; 0.67]$} & 0.458 \\
\hline $\begin{array}{l}\text { Anderson, J.E. and D. Marcouiller (2002) } \\
\text { Rev. of Econ. and Stat. }\end{array}$ & 1996 & 6 & {$[1.095 ; 1.134]$} & 1.117 \\
\hline $\begin{array}{l}\text { Bergstrand, J.H. (1985) } \\
\text { Rev. of Econ. and Stat. }\end{array}$ & $1965-76$ & 8 & {$[0.69 ; 0.78]$} & 0.738 \\
\hline $\begin{array}{l}\text { Bergstrand, J.H. (1989) } \\
\text { Rev. of Econ. and Stat. }\end{array}$ & $1965-76$ & 36 & {$[0.36 ; 2.80]$} & 1.053 \\
\hline $\begin{array}{l}\text { Bröcker, J. and H.C. Rohweder (1990) } \\
\text { Annals of Regional Science }\end{array}$ & $1968-83$ & 10 & {$[0.153 ; 0.212]$} & 0.176 \\
\hline $\begin{array}{l}\text { Brown, W.M. and W.P. Anderson (2002) } \\
\text { Papers in Regional Science }\end{array}$ & 1993 & 18 & {$[-0.043 ; 1.233]$} & 0.839 \\
\hline $\begin{array}{l}\text { Ceglowski, J. (2000a) } \\
\text { North Amer. J. of Econ. and Finance }\end{array}$ & $1988-96$ & 56 & {$[1.26 ; 1.61]$} & 1.407 \\
\hline $\begin{array}{l}\text { Ceglowski, J. (2000b) } \\
\text { J. of Econ. Integration }\end{array}$ & $1988-96$ & 52 & {$[1.11 ; 1.34]$} & 1.227 \\
\hline $\begin{array}{l}\text { Christerson, B. (1994) } \\
\text { Intern. Regional Science Rev. }\end{array}$ & 1987 & 8 & {$[0.98 ; 2.29]$} & 1.720 \\
\hline $\begin{array}{l}\text { de Ménil G. and M. Maurel (1994) } \\
\text { Weltwirtschaftliches Archiv }\end{array}$ & $1924-26$ & 4 & {$[0.701 ; 0.706]$} & 0.704 \\
\hline $\begin{array}{l}\text { Djankov, S. and C.L. Freund (2002) } \\
\text { J. of Comparative Econ. }\end{array}$ & $1987-96$ & 10 & {$[0.42 ; 1.16]$} & 0.793 \\
\hline $\begin{array}{l}\text { Dunlevy, J.A. and W.K. Hutchinson (1999) } \\
\text { J. of Econ. History }\end{array}$ & $1870-1910$ & 16 & {$[0.45 ; 2.62]$} & 0.992 \\
\hline $\begin{array}{l}\text { Egger, P. }(2000) \\
\text { Econ. Letters }\end{array}$ & $1985-96$ & 3 & {$[1.08 ; 1.23]$} & 1.147 \\
\hline $\begin{array}{l}\text { Feenstra, R.C. (2002) } \\
\text { Scottish J. of Polit. Econ. }\end{array}$ & 1993 & 3 & {$[1.11 ; 1.35]$} & 1.237 \\
\hline $\begin{array}{l}\text { Feenstra, R.C. et al. (2001) } \\
\text { Canadian J. of Econ. }\end{array}$ & $1970-90$ & 36 & {$[0.49 ; 1.39]$} & 0.994 \\
\hline $\begin{array}{l}\text { Fitzsimons, E. et al. (1999) } \\
\text { Econ. and Social Rev. }\end{array}$ & $1970-92$ & 6 & {$[0.500 ; 0.655]$} & 0.593 \\
\hline $\begin{array}{l}\text { Freund, C.L. and D. Weinhold (2002) } \\
\text { American Econ. Rev. }\end{array}$ & 1995-99 & 4 & {$[0.08 ; 0.42]$} & 0.243 \\
\hline $\begin{array}{l}\text { Garman, G. et al. (1998) } \\
\text { J. of Applied Business Research }\end{array}$ & $1970-90$ & 13 & {$[1.554 ; 2.326]$} & 2.063 \\
\hline $\begin{array}{l}\text { Ghoshal, A. (1997) } \\
\text { Indian J. of Applied Econ. }\end{array}$ & $1985-94$ & 12 & {$[0.74 ; 0.99]$} & 0.839 \\
\hline
\end{tabular}




\begin{tabular}{|c|c|c|c|c|}
\hline Authors and References & Time Period & $\begin{array}{l}\text { Nb. of } \\
\text { Estimates }\end{array}$ & Ranges & Mean \\
\hline $\begin{array}{l}\text { Harris, M.N. and L. Matyas (2001) } \\
\text { Asia Pacific J. of Econ. and Business }\end{array}$ & 1979-97 & 9 & {$[0.057 ; 1.084]$} & 0.826 \\
\hline $\begin{array}{l}\text { Head, K. and J. Ries (1998) } \\
\text { Canadian J. of Econ. }\end{array}$ & $1980-92$ & 8 & {$[0.208 ; 1.474]$} & 0.743 \\
\hline $\begin{array}{l}\text { Helliwell, J.F. (1996) } \\
\text { Canadian J. of Econ. }\end{array}$ & $1988-90$ & 12 & {$[0.96 ; 1.44]$} & 1.269 \\
\hline $\begin{array}{l}\text { Helliwell, J.F. (1997) } \\
\text { Pacific Econ. Rev. }\end{array}$ & $1988-92$ & 24 & {$[0.678 ; 1.610]$} & 1.048 \\
\hline $\begin{array}{l}\text { Helliwell, J.F. and G. Verdier (2001) } \\
\text { Canadian J. of Econ. }\end{array}$ & 1991-96 & 3 & 1.411 & 1.411 \\
\hline $\begin{array}{l}\text { Hirsch, S. and N. Hashai (2000) } \\
\text { Intern. Trade J. }\end{array}$ & 1993 & 66 & {$[0.061 ; 0.886]$} & 0.343 \\
\hline $\begin{array}{l}\text { Jakab, Z.M. et al. (2001) } \\
\text { J. of Comparative Econ. }\end{array}$ & 1990-97 & 6 & {$[0.893 ; 1.01]$} & 0.944 \\
\hline $\begin{array}{l}\text { Larue, B. and J. Mutunga (1993) } \\
\text { Intern. Econ. J. }\end{array}$ & $1973-88$ & 4 & {$[0.26 ; 0.81]$} & 0.615 \\
\hline $\begin{array}{l}\text { Lopez-Cordova, J.E. and C. Meissner (2003) } \\
A E R\end{array}$ & $1870-1910$ & 12 & {$[0.349 ; 0.977]$} & 0.691 \\
\hline $\begin{array}{l}\text { Loungani, P. et al. (2002) } \\
\text { Scottish J. of Polit. Econ. }\end{array}$ & 1981-98 & 4 & {$[0.292 ; 0.923]$} & 0.698 \\
\hline $\begin{array}{l}\text { Mathur, S.K. (1999-2000) } \\
\text { Indian Econ. J. }\end{array}$ & $1991-94$ & 12 & {$[0.473 ; 1.729]$} & 0.979 \\
\hline $\begin{array}{l}\text { Mumenthaler, S. (1999) } \\
\text { Aussenwirtschaft }\end{array}$ & $1971-95$ & 19 & {$[0.140 ; 0.669]$} & 0.384 \\
\hline $\begin{array}{l}\text { Nitsch, V. (2000) } \\
\text { Canadian J. of Econ. }\end{array}$ & $1979-90$ & 16 & {$[0.56 ; 1.16]$} & 0.851 \\
\hline $\begin{array}{l}\text { Portes, R. and H. Rey (1998) } \\
\text { J. of the Japanese and Intern. Econ. }\end{array}$ & 1989-96 & 1 & 0.544 & 0.544 \\
\hline $\begin{array}{l}\text { Sanso, M. et al. (1993) } \\
\text { Rev. of Econ. and Stat. }\end{array}$ & $1965-87$ & 7 & {$[0.56 ; 0.80]$} & 0.720 \\
\hline $\begin{array}{l}\text { Sapir, A. (2001) } \\
\text { European J. of Polit. Econ. }\end{array}$ & 1960-92 & 33 & {$[0.50 ; 0.86]$} & 0.675 \\
\hline $\begin{array}{l}\text { Smarzynska, B.K. (2001) } \\
\text { J. of Econ. Integration }\end{array}$ & $1970-90$ & 10 & {$[0.57 ; 0.97]$} & 0.739 \\
\hline $\begin{array}{l}\text { Soloaga, I. and A. Winters (2001) } \\
\text { North Amer. J. of Econ. and Finance }\end{array}$ & 1980-96 & 20 & {$[0.90 ; 1.09]$} & 1.003 \\
\hline $\begin{array}{l}\text { Stone, S.F. and B.N. Jeon (2000) } \\
\text { J. of Econ. Integration }\end{array}$ & 1987-93 & 7 & {$[0.43 ; 0.64]$} & 0.536 \\
\hline $\begin{array}{l}\text { Tamirisa, N.T. (1999) } \\
\text { IMF Staff Papers }\end{array}$ & 1996 & 27 & {$[0.58 ; 1.07]$} & 0.851 \\
\hline $\begin{array}{l}\text { Thornton, J. and A. Goglio (2002) } \\
\text { Applied Econ. Letters }\end{array}$ & 1976-96 & 12 & {$[0.162 ; 0.285]$} & 0.232 \\
\hline Thoumi, F.E. (1989) & 1971-75 & 12 & {$[0.823 ; 1.449]$} & 1.105 \\
\hline \multicolumn{5}{|c|}{ Continued on next page } \\
\hline
\end{tabular}




\begin{tabular}{|c|c|c|c|c|}
\hline $\begin{array}{l}\text { Authors and References } \\
\text { Social and Econ. Studies }\end{array}$ & Time Period & $\begin{array}{c}\text { Nb. of } \\
\text { Estimates }\end{array}$ & Ranges & Mean \\
\hline $\begin{array}{l}\text { Wagner, D. et al. (2002) } \\
\text { Scottish J. of Polit. Econ. }\end{array}$ & 1992-95 & 6 & {$[1.05 ; 1.85]$} & 1.467 \\
\hline $\begin{array}{l}\text { Wolf, H.C. (2000a) } \\
\text { Rev. of Econ. and Stat. }\end{array}$ & 1993 & 6 & {$[0.75 ; 1.02]$} & 0.855 \\
\hline $\begin{array}{l}\mathrm{Xu}, \mathrm{X} .(2000) \\
\text { Environmental and Resource Econ. }\end{array}$ & 1990 & 6 & {$[0.81 ; 0.94]$} & 0.885 \\
\hline \multicolumn{5}{|c|}{ Published studies in a book } \\
\hline $\begin{array}{l}\text { Eichengreen, B. and D.I. Irwin (1998) } \\
\text { in Frankel J.A. (ed) }\end{array}$ & $1928-64$ & 31 & {$[0.13 ; 0.98]$} & 0.543 \\
\hline $\begin{array}{l}\text { Frankel, J.A. et al. (1998) } \\
\text { in Frankel J.A. (ed) }\end{array}$ & $1970-90$ & 4 & {$[0.50 ; 0.51]$} & 0.505 \\
\hline $\begin{array}{l}\text { Frankel, J.A. and S.-J. Wei (1998) } \\
\text { in Frankel J.A. (ed) }\end{array}$ & $1965-92$ & 26 & {$[0.40 ; 0.93]$} & 0.684 \\
\hline $\begin{array}{l}\text { Wolf, H.C. (2000b) } \\
\text { in Hess G.D. and E. van Wincoop (eds) }\end{array}$ & 1993 & 4 & {$[1.252 ; 1.487]$} & 1.387 \\
\hline \multicolumn{5}{|c|}{ Working Papers } \\
\hline $\begin{array}{l}\text { Al, A.H. and T. Yousef }(2000) \\
\text { IMF Working Paper \#10 }\end{array}$ & $1995-97$ & 6 & {$[1.01 ; 1.61]$} & 1.215 \\
\hline $\begin{array}{l}\text { Brülhart, M. and F. Trionfetti (1999) } \\
\text { Univ. de Lausanne Cahiers de Recherches } \\
\text { Econ. \# } 9918\end{array}$ & $1970-85$ & 9 & {$[0.90 ; 1.50]$} & 1.104 \\
\hline $\begin{array}{l}\text { Matyas, L. et al. (1997) } \\
\text { Monash Department of Econometrics and } \\
\text { Stat. Working Paper }\end{array}$ & $1978-97$ & 4 & {$[0.8244 ; 0.8756]$} & 0.855 \\
\hline $\begin{array}{l}\text { Nagy, A.M. (1997) } \\
\text { Univ. of Birmingham, Department of Econ. } \\
\text { Discussion Paper \# } 20\end{array}$ & $1985-95$ & 6 & {$[0.75 ; 0.87]$} & 0.807 \\
\hline $\begin{array}{l}\text { Portes, R. and H. Rey }(2000) \\
\text { CIDER Working Paper \# } 111\end{array}$ & $1989-96$ & 2 & {$[0.235 ; 0.544]$} & 0.390 \\
\hline $\begin{array}{l}\text { Wei, S.-J. (1996) } \\
\text { NBER Working Paper \# } 5531\end{array}$ & $1982-94$ & 24 & {$[0.78 ; 1.08]$} & 0.912 \\
\hline $\begin{array}{l}\text { Wolf, H.C. (1997) } \\
\text { NBER Working Paper \# } 5939\end{array}$ & 1993 & 14 & {$[0.126 ; 1.030]$} & 0.425 \\
\hline \multicolumn{5}{|c|}{ HIGH QUALITY REVIEW SAMPLE } \\
\hline $\begin{array}{l}\text { Aitken, N.D. (1973) } \\
\text { American Econ. Rev. }\end{array}$ & $1951-67$ & 18 & {$[0.349 ; 0.509]$} & 0.438 \\
\hline $\begin{array}{l}\text { Amiti, M. and K. Wakelin (2003) } \\
\text { J. of Intern. Econ. }\end{array}$ & $1986-94$ & 16 & {$[0.69 ; 0.92]$} & 0.818 \\
\hline $\begin{array}{l}\text { Anderson, J.E. and E. van Wincoop (2003) } \\
\text { American Econ. Rev. }\end{array}$ & 1993 & 6 & {$[1.08 ; 1.35]$} & 1.183 \\
\hline $\begin{array}{l}\text { Bougheas, S., P.O. Demetriades, E.L.W. } \\
\text { Morgenroth (1999) }\end{array}$ & $1970-90$ & 10 & {$[0.24 ; 0.78]$} & 0.57 \\
\hline \multicolumn{5}{|c|}{ Continued on next page } \\
\hline
\end{tabular}




\begin{tabular}{|c|c|c|c|c|}
\hline $\begin{array}{l}\text { Authors and References } \\
\text { J. of Intern. Econ. }\end{array}$ & Time Period & $\begin{array}{l}\text { Nb. of } \\
\text { Estimates }\end{array}$ & Ranges & Mean \\
\hline $\begin{array}{l}\text { Brada, J.C. and J.A. Mendez (1985) } \\
\text { Rev. of Econ. and Stat. }\end{array}$ & $1970-76$ & 3 & {$[0.472 ; 0.581]$} & 0.472 \\
\hline $\begin{array}{l}\text { Chen, N. }(2003) \\
\text { J. of Intern. Econ. }\end{array}$ & 1996 & 39 & {$[0.88 ; 1.80]$} & 1.510 \\
\hline $\begin{array}{l}\text { Evans C. (2003) } \\
\text { American Econ. Rev. }\end{array}$ & 1989-1994 & 50 & {$[0.45 ; 0.95]$} & 0.745 \\
\hline $\begin{array}{l}\text { Frankel, J.A. and D. Romer (1999) } \\
\text { American Econ. Rev. }\end{array}$ & 1985 & 1 & 0.85 & 0.85 \\
\hline $\begin{array}{l}\text { Freund, C.L. and D. Weinhold (2004) } \\
\text { J. of Intern. Econ. }\end{array}$ & 1995-99 & 5 & {$[0.216 ; 0.885]$} & 0.704 \\
\hline $\begin{array}{l}\text { Ghosh, S. and S. Yamarik (2003) } \\
\text { J. of Intern. Econ. }\end{array}$ & $1970-95$ & 1 & 1.204 & 1.204 \\
\hline $\begin{array}{l}\text { Irwin, D.A. and M. Tervio (2002) } \\
\text { J. of Intern. Econ. }\end{array}$ & 1913-90 & 11 & {$[0.55 ; 1.14]$} & 0.78 \\
\hline $\begin{array}{l}\text { McCallum, J. (1995) } \\
\text { American Econ. Rev. }\end{array}$ & 1988 & 11 & {$[1.23 ; 2]$} & 1.503 \\
\hline $\begin{array}{l}\text { Pelzman, J. (1977) } \\
\text { American Econ. Rev. }\end{array}$ & $1954-70$ & 5 & {$[0.323 ; 1.509]$} & 0.776 \\
\hline $\begin{array}{l}\text { Rauch J. (1999) } \\
\text { J. of Intern. Econ. }\end{array}$ & $1970-90$ & 36 & {$[0.595 ; 1.117]$} & 0.842 \\
\hline $\begin{array}{l}\text { Rauch, J.E. and V. Trindade (2002) } \\
\text { Rev. of Econ. and Stat. }\end{array}$ & $1980-90$ & 24 & {$[0.677 ; 1.416]$} & 1.014 \\
\hline $\begin{array}{l}\text { Redding, S. and A.J. Venables (2004) } \\
\text { J. of Intern. Econ. }\end{array}$ & 1994 & 3 & {$[1.353 ; 1.738]$} & 1.543 \\
\hline $\begin{array}{l}\text { Rose, A.K. (2004) } \\
\text { American Econ. Rev. }\end{array}$ & 1948-99 & 12 & {$[1.12 ; 1.31]$} & 1.206 \\
\hline $\begin{array}{l}\text { Rose, A.K. and E. van Wincoop (2001) } \\
\text { American Econ. Rev. }\end{array}$ & $1970-95$ & 2 & {$[1.06 ; 1.31]$} & 1.185 \\
\hline $\begin{array}{l}\text { Smith, P.J. }(2001) \\
\text { J. of Intern. Econ. }\end{array}$ & 1989 & 2 & {$[0.78 ; 0.81]$} & 0.795 \\
\hline $\begin{array}{l}\text { Summary, R.M. (1989) } \\
\text { Rev. of Econ. and Stat. }\end{array}$ & $1978-82$ & 4 & {$[0.43 ; 0.62]$} & 0.53 \\
\hline $\begin{array}{l}\text { Thursby, J.G. and M.C. Thursby (1987) } \\
\text { Rev. of Econ. and Stat. }\end{array}$ & $1974-82$ & 17 & {$[0.358 ; 7.279]$} & 1.726 \\
\hline $\begin{array}{l}\text { Wolf, C.Jr. and D. Weinschrott (1973) } \\
\text { American Econ. Rev. }\end{array}$ & $1963-65$ & 4 & {$[0.69 ; 0.73]$} & 0.71 \\
\hline $\begin{array}{l}\text { Wong, W.-K. (2004) } \\
\text { J. of Intern. Econ. }\end{array}$ & 1984 & 1 & 0.84 & 0.84 \\
\hline
\end{tabular}

